\title{
The 30th international symposium on paediatric surgical research
}

\author{
Prem Puri ${ }^{1}$
}

Accepted: 21 September 2017 / Published online: 5 October 2017

(C) Springer-Verlag GmbH Germany 2017

The 30th International Symposium on Paediatric Surgical Research (ISPSR) was held at The Lalit Hotel, New Delhi, India from 8 to 10 September 2017. This was the first time that the ISPSR was held in India and only the second time in Asia. This was a highly successful meeting in which 165 papers on paediatric surgical research were presented. As always, the highlight of the symposium was the Prize Session. There were ten excellent papers presented at this session. The Prem Puri Basic Science Research Prize was awarded to Dr. Agnes S. Klar from Zurich, Switzerland for her presentation on "Characterization of M1 and M2 polarization of macrophages in vascularized human dermoepidermal skin substitutes in vivo". The Michael Höllwarth Clinical Research Prize was awarded to Dr. Hiroki Nakamura from Dublin, Ireland for his presentation on "Altered goblet cell function in Hirschsprung's disease".

The International Board of Paediatric Surgical Research thanks Professor Devendra K. Gupta and his team for a highly successful meeting in New Delhi.

On behalf of the Scientific Committee of the International Board of Paediatric Surgical Research.

Prem Puri

Prem.puri@ncrc.ie

1 National Children's Research Centre, Our Lady's Children's

Hospital, Crumlin, Dublin, Ireland 